\title{
Black and Beautiful: A Content Analysis and Study of Colorism and Strides toward Inclusivity in the Cosmetic Industry
}

\author{
Cynthia M. Frisby \\ Department of Strategic Communication, Missouri School of Journalism, University of Missouri, Columbia, USA \\ Email: frisbyc@missouri.edu
}

How to cite this paper: Frisby, C. M. (2019). Black and Beautiful: A Content Analysis and Study of Colorism and Strides toward Inclusivity in the Cosmetic Industry. Advances in Journalism and Communication, 7, 35-54.

https://doi.org/10.4236/ajc.2019.72003

Received: March 27, 2019

Accepted: June 16, 2019

Published: June 19, 2019

Copyright $\odot 2019$ by author(s) and Scientific Research Publishing Inc. This work is licensed under the Creative Commons Attribution International License (CC BY 4.0).

http://creativecommons.org/licenses/by/4.0/

\section{(c) (i) Open Access}

\begin{abstract}
The purpose of this research is twofold: 1) to explore colorism in the cosmetic industry in light of multiple marketing venues such as social media, online, and retail stores and 2) to provide a snapshot of improvement (or lack of) in shades and foundation colors offered in the beauty industry. A Kolmogorov-Smirnov test conducted indicates that the total shades of foundation found in a sample of 49 cosmetic beauty brands do not follow a normal distribution, $D(49)=.360, p=.0000$. In addition, a Chi-Square goodness-of-fit test conducted also shows that the variety in foundation shades is also not equally distributed ( $\chi^{2}=68.7$, df, $47, p<.0001$ ), suggesting that significant differences exist between the total number of foundation shades offered by cosmetic brands with higher numbers of shades found in the "light to medium" skin tones. Implications of these findings are discussed in terms of directions for the need for darker shades and images that show that black is beautiful along with suggestions for future research on colorism, beauty, and American standards and biases towards beauty.
\end{abstract}

\section{Keywords}

Content Analysis, Colorism, Skin Tone, Beauty and Skin Tone, Marketing Beauty

\section{Introduction}

"Good hair, light skin, you must be smart, if you re black, you' re dark-skinned, you' re ugly. That really happens. This is something that started with slavery, when they divided the house, and it's still a part of today's society and things that we battle with"-Rapsody. 
What is embedded in many marketing and advertising messages is the idea that women need cosmetics to cover blotches and dark spots, stop aging effects, and enhance physical attractiveness. If truth be told, what is behind the messages entrenched in many advertisements for cosmetics is the idea that regardless of one's ethnicity, [most] women have issues with their complexion and need a product, like foundation, that enhances deficits in facial appearance and will ultimately increase one's level of physical attractiveness. Add to that idea that at one point in American history retail stores used to offer limited cosmetic products that could be used by women of color (Nittle, 2018a). That all changed when in September of 2017, Rhianna introduced her brand Fenty and its 40 shades.

After years of limitations in shades for black women, it seems that the entry of Rhianna's Fenty brand in 2017 started a new trend in beauty; all of a sudden major marketers in the cosmetic industry began to expand offerings of foundation shades from the traditional six shades to now providing $40+$ shades for women of all shades and skin tones. This market trend in cosmetics led to the research that guided this work; we were interested in determining if beauty market started to offer shades that are tailored to women of darker skin tones and complexions? To answer this question, a formative research study was conducted to determine how the cosmetic industry has responded to issues of inclusivity and diversity by examining a specific observational measurement evaluation: the availability of foundation shades that match darker skin tones. In other words, this study answers the aforementioned research question by examining the extent to which make-up for skin tones that do not match our culture's traditional standards of beauty (light is beautiful) can be found in today's cosmetic and makeup industry.

\subsection{Significance and Contribution}

Often in American culture, it is believed by some that dark skinned women are thought of as being "ugly", are less educated because of the dark skin tone and/or are less attractive. As a result, women with darker skin tones are often socially disadvantaged and treated as second-class citizens existing beneath women with lighter skin tones and complexions. This paper hopes to show that the darker skin tone color is beautiful, valued, significant, and loved. We want to show that being Black is also beautiful.

A legendary nursery rhyme for children illustrates and underscores the claim previously made in the preceding paragraph;

"If you' re black, stay back,

If you' re brown, stick around;

If you' re yellow, you' re mellow,

If you' re white, you' re all right'.

Colorism is and continues to be an unyielding stumbling block for blacks living in America. Colorism refers to "a process that privileges light-skinned people of color over dark in areas such as income, education, housing, and the marriage 
market" (Hunter, 2007). What is not known is whether or not colorism has been addressed and showing signs of improvement in the beauty industry. Results obtained in the current study may provide insights on enhancements conducted in terms of marketing cosmetic foundation to women of darker skin complexions. Specifically, the study hopes to provide empirical evidence that demonstrates strides made in the cosmetic industry that show that the industry has heard the voices of darker skin toned women and in response have expanded product lines to include cosmetics like foundation that can and will fit a wide array of skin tones and complexions. Moreover, few, if any, published scholarly works could be located that investigate colorism and the marketing of makeup in the cosmetic industry. While several studies have been published on the effects of colorism in media, Hollywood, business, and interpersonal relationships, little work has been conducted on the colorism in the cosmetic industry. Thus, this research seeks to expand on studies that examine attitudes and opinions held by women of color on colorism in makeup shades by filling a gap in the literature that offers an academic, pragmatic research perspective and data in an unchartered area.

\subsection{Research Goals and Questions}

Although empirical studies and scholarship have yielded invaluable information on the manifestations and effects of colorism in other areas (i.e. income, employment, entertainment, media), few published scholarly studies have directly focused on obtaining systematic, empirical data on cosmetics and the makeup industry. Yet, even fewer scholarly studies were found that address the everyday experience of colorism in terms of finding the right shade of makeup for women of color. Hence, the following research objectives were established to help develop the literature review and the associated methodology;

1) To fulfill the researcher's curiosity and need for greater understanding about colorism in the beauty industry. Related to this goal, the author wanted to test the feasibility of starting a more in depth study in this area on the depth and breadth of shades offered by beauty brands that will match a broader variety of skin tones and shades;

2) To develop a beginning foundation of a theoretical framework encapsulating the key features of colorism in the 21 st century in the beauty industry;

3) To produce culturally relevant knowledge on another aspect of colorism in American culture that will inform recommendations for changes in the marketing, advertising, entertainment, business, and journalism industries.

Victims of colorism often feel pressure to cover up their dark skin tones with lighter foundation shades. Dark-skin women have repeatedly expressed the need and offered commentary on the social pressures they feel to sexualize themselves in order to appeal to others (see, for example "Oprah Winfrey's" "Dark Skin Girl” documentary, also refer to Goodine, 2018; Moné, 2018; O’Brien, 2009). Therefore the present research was crafted to contribute to the field of communication broadly, but more specifically for scholars interested in multicultural, 
gender, and inclusivity academic, empirical research. Data obtained in the current study specifically addresses how the beauty industry has responded to issues of colorism in marketing of their products.

Purposely, two research questions were formulated to guide the research:

RQ1: To what extent are cosmetics available for skin tones that more closely resemble women of darker skin tones and pigmentation?

RQ2: How difficult is it to foundation for darker skin tones? To what extent will darker shades be offered in other outlets like Variety stores (e.g. Wal-Mart, Target, etc.), Department stores, and online, E-commerce outlets?

\section{Background}

\subsection{Buying Power of African American Women Dollar}

Marketing research shows that many African American women will spend twice as much money on skin care products than the general market simply because they have to go through a trial and error process to find the right shade of foundation (Bryant, 2016). This trial and error process ultimately generates billions of dollars for the cosmetic industry but at the expense of women of color. It seems that the beauty industry may want to focus on including shades made for darker skin tones instead of marginalizing these complexions and forcing women to engage in the cycle of trial and error.

In fact, in a recent report, it was documented that women of color "spend nearly nine times more than our non-Black counterparts on ethnic hair and beauty products" (Harmon, 2018). Research also informs us that black consumers define mainstream culture and shows that buying habits of black consumers also influences how non-Black consumers spend their money (Harmon, 2018). This information clearly mandates the need for women of color, and all diverse consumers, to see themselves authentically represented in marketing of beauty brands. This background on the beauty industry and women of color shows that not only is the current study important and needed (it will show which beauty brands are paying attention and who listened to women of color), but data obtained will also shed light on those beauty brands who listened and continue to listen to the needs of women with darker skin tones and complexions.

According to research firm Kline \& Company, the multicultural beauty market is growing fast with brands that market toward minorities growing from 3.7 percent in 2014, to 4.8 percent in 2018 (reported in Marketing News, 2018). According to the US Census the majority of Americans will belong to an ethnic minority group by 2044 , therefore, to keep up with the demand, the make-up industry must offer products for a diverse market with complex needs for foundation that will match a particular skin tone. Research suggests that approximately $\$ 7.5$ billion is spent on beauty products annually, which translates to a purchase rate of $80 \%$ more on cosmetics and twice as much on skincare than any other consumer (Marketing News, 2018; Segran, 2015). This statistic becomes even more enlightening when we consider that market research data demon- 
strates that in terms of the heaviest buyer of cosmetic products are women of color (Marketing News, 2018). Women of color, it has been documented, spend much of their disposable income on makeup.

\subsection{History of Colorism in American Culture}

Colorism is a demonstrated bias toward lighter-skin tones and often refers to explicit discrimination based on skin color. People who are dark-skinned are often disadvantaged while those with lighter skin tones are offered greater opportunities, resources, and privileges. Published research on colorism associates this phenomenon to social disparities for those with darker skin tones in categories like smaller incomes, lower marriage rates, fewer job opportunities, longer prison terms and fewer job prospects. "Job advertisements from the mid-20th century reveal that African-Americans with light skin clearly believed their coloring would make them better job candidates" (Nittle, 2018b).

Colorism in America has been traced back to slavery times when slave owners gave preferential treatment to slaves with lighter skin tones and complexions. Historical records reveal that during slavery, skin color was a discriminatory characteristic among African-American slaves and Caucasian slave owners (Hall, 1995; Robinson \& Ward, 1995; Wade \& Bielitz, 2005). Those darker-skinned slaves worked outside in the fields while the lighter-skinned slaves worked inside the home and were often given less physically grueling domestic chores (Wade \& Bielitz, 2005). African-Americans whose physical features (lips, nose, and body shape) resembled European Americans were thought to be more attractive and appealing than those whose features were seen as being "too Black" or "Negroid" (Hall, 1995; Wade \& Bielitz, 2005). It was also during slavery when slave owners were known to treat light-skinned slaves as family members. It was also a time when slave owners frequently forced light-skin slave women to engage in sexual encounters that resulted in and mixed or biracial, light-skin offspring. This background in our culture's history provides the framework for understanding how light skin came to be viewed as an asset in American culture.

\subsection{Colorism in the Makeup Industry}

Even though makeup lines for black women in the 1940's were prevalent, beauty companies focused many of their advertising efforts on appealing to black women through the use of skin lightening products often promoted as "blemish creams". Products and merchandise aimed at African-Americans also perpetuated skin color biases by frequently utilizing actors and models with light-skin tones (Fears, 1998; Watson, Thornton, \& Engelland, 2010). Thus, it should be no surprise that colorism has been a controversial topic in a wide-range of areas for African-Americans since slavery (Wade \& Bielitz, 2005).

Light skin was so coveted in American history that skin-lightening and whitening creams were and still continue to be best-sellers in the 21st century (Nittle, 2018b). In fact, research shows that Mexican-American women in Arizona, 
California, and Texas have reportedly "suffered mercury poisoning after using whitening creams to bleach their skin" (Nittle, 2018b). Thus, it should be no surprise that skin-lightening products sold by cosmetic manufacturers were made exclusively for women with darker skin tones with the covert message that the product will lighten the skin and result in fairer, lighter more attractive skin tones.

After a careful review of the history of colorism in the makeup industry, one major theme was discovered: the range of shades available in the makeup industry was often limited, leaving women of color with darker skin complexions unable to find a shade that even vaguely resembles their own. This finding along with the history of colorism and its impact in the cosmetic industry led to the formulation of the first research question:

RQ1: To what extent are cosmetics available for skin tones that more closely resemble women of darker skin tones and pigmentation?

\subsection{Foundation as a Cosmetic Skin-Coloring Tool}

Foundation for the purposes of this paper has been operationalized as a "skin-colored cosmetic application used to even out skin tone, blur pores, hide imperfections and make skin appear smoother" (Goins, 2019). Foundation, or facial cosmetics, is an item in the beauty industry that started to produce shades for fair to moderate skin tones, leaving women with darker skin hues out of the market and unable to use or purchase foundation like women with lighter skin tones were able to do. It was common to find that most product lines seem to include the skin tones of various women whose complexions can be identified as "fair to moderate" but when looking at a fuller scale of tones available, it was apparent that the darker end of the skin tone spectrum was non-existent. Given this information, the current study seeks to determine if the darker end of the skin tone spectrum is currently in existence for women whose complexions may be darker.

\subsection{Difficulties Finding the Right Shade}

After a doing a recent survey of roughly 5500 women of color Tomi Gbeleyi, a former model obtained responses that showed over $80 \%$ percent of the women who participated in the study reporting extreme difficulties finding the right foundation shade (reported in Payne, 2018). Implications of the data obtained suggested to Gbelevi and her team of researchers that when one considers the enormous number of beauty brands available to women, $80 \%$ of a total of 5,500 women ( $n=4000$ women of color) feel that it is difficult finding the right foundation, then we have a huge problem in the cosmetic industry (see Payne, 2018).

\section{If Not in Stores, Then Where?}

The make-up industry, according to market research, generated close to $\$ 42$ billion in 2017 (Report Linker, 2018). Out of all the product categories in the cosmetic industry, foundation which is considered to be a face cosmetic represented 
the leading market segment, with over $\$ 12$ billion in sales revenue in 2018 and accounting for more than $35 \%$ of overall market value (Report Linker, 2018). According to recent market research statistics, many cosmetics manufacturers are concentrating on providing ranges in products so that they no long just offer differences in color, but that products produce the same benefits for women of all backgrounds and skin tones.

Innovation and product development in the make-up industry has led to a wider range of cosmetics that are being offered in new formats and new textures. Make-up products are usually sold through various outlets; Variety stores like Wal-Mart, Wal-Greens, Target, and grocery store retailers; Retail outlets that include department stores and specialty retail stores also provide alternatives to purchase cosmetics; and of more recent trends, cosmetic marketers have started to embrace E-Commerce, which includes online marketing to their distribution outlet also have seen major success. We also know from marketing research that when beauty brands make their products available online, sales increase, especially given that the online sales are primarily driven by African American and Hispanic women. The greatest challenge for many women of color is the issue of having opportunities to walk in a retail or specialty store and finding darker shades on the shelf or in stock. To combat this hurdle, Rihanna's Fenty product, Pro Filt'R Foundation, offers consumers 40 shades+, which are available at a specialty retail outlet, Sephora and also online. The information provided on the increase of online marketing led to the formulation of the second research question:

RQ2: How difficult is it for women to find matching foundation for darker skin tones? In other words, to what extent will darker shades be offered in other outlets like Variety stores (e.g. Wal-Mart, Target, etc.), Department stores, and online, E-commerce retail venues?

Based on the review of the literature, it is evident that data obtained from this study have significant implications for how people from different cultures and races are represented in the beauty and cosmetic industry, industries that perpetuate beauty ideals. While numerous studies have analyzed colorism in American culture, there is little research on colorism in the beauty industry, and little to no research has been conducted on beauty brands that market cosmetics and foundations for and targeted to women of darker skin tones.

\section{Methodology}

A content analysis was designed and conducted for this study to test the statistical significance of relationships between beauty brands and total number of foundation shades offered. Content analysis is a quantitative research method that involves exploring the images and representation of subordinate groups in a representative sampling of media (Berger, 1991). Krippendorff (2004), defines content analysis in relation to this study as the analysis of the manifest and latent content of a body of communicated material (beauty brands) through classification, tabulation, and evaluation of its keys symbols and themes in orders to as- 
certain its meaning and probable effect. Similarly, Mittell (2004) defines content analysis as the setting of specific boundaries to measure within a selected group of programs and count the appearance of characters that fit into the identified categories. Mittell (2004) also suggests that content analysis is best for answering questions where the coding groups are clear-cut and objective such as with partisan media and the type of frame used.

To evaluate the extent to which beauty brands in today's current market have addressed issues of colorism, we analyzed 49 beauty brands for six months during the 2018-2019 academic year. We began our study period in Fall of 2018 to capture a true picture of as many beauty brands that are available for consumers of all ethnic backgrounds.

\subsection{Rationale for Using Formulative Research}

Since the study sought to explore the phenomenon of makeup available for darker skin tones, the research called for a more exploratory or descriptive methodological procedure (Denzin \& Lincoln, 2005). Through exploratory research designs such as the one used in the current study, data presented will highlight crucial research problems for future studies and investigations. While the methodology and statistics employed in the study are not complex or advanced, we must recognize that this study is important because it puts the issue of colorism in cosmetics front and center in scholarly journals. Therefore, it was determined that the investigator needed to begin with a study that will acquaint readers and other interested persons with the problem or concept to be researched which will ultimately produce hypotheses to be tested in future research.

Formulative (i.e. exploratory) research is often employed in a study when a researcher has an idea or has observed something and seeks to understand more about the phenomenon. A formulative research study, therefore, is an attempt to lay the groundwork that will lead to future studies or to determine if what is being observed might be explained by a currently existing theory. Since the current study seeks to break new ground in an unchartered research territory, this approach was deemed most appropriate due to the fact that the data obtained delivers new information about colorism in the cosmetic industry. Therefore, the main contribution that this study offers is that data and findings obtained can be hugely useful for future social research. It is believed that the research and associated findings are important because this study is breaking new ground and will deliver data about colorism in a new, relatively unchartered area such as the cosmetic industry.

\subsection{Search Terms}

To obtain a sample of beauty brands, the following search terms were used: "foundation", "beauty", "cosmetics", "foundation shades", "shades of color in beauty", "makeup for women", "women of color and foundation", "make up for women of color", "'popular beauty brands", "make-up and foundation", "wom- 
en and beauty brands", "colorism", “colorism in beauty brands", "make-up and colorism", "shades of foundation", "dark skin tone makeup and foundation", "beauty brands with widest foundation range", "lack of diversity in makeup/foundation", "total number of foundation shades" "foundation shades for darker-skin tones", "brands with over 10 shades in foundation", "marketing colorism", and "women of color, make-up and colorism". We searched entire magazines, retail stores such as Sephora and a search of websites. For example, one of the coders along with the principal investigator would visit variety stores and department stores to check for brands not included from the website Google search. We merged our lists and then reviewed brand names and excluded those that were no longer available. From this search, we were able to obtain a total of 49 brands, which also served as our unit of analysis.

Since the objective of the present study was to analyze the availability of foundation for darker skin tones, we also gathered data on the total number of shades each beauty brand had in a specific skin tone category. Thus, data for this study were obtained through a content analysis on the website pages and/or brochures or retail store displays of 49 beauty brands (see Table 1).

The author and one of three coders tallied the total number of shades available from these 49 beauty brands while another coder tallied the types of shades available (see Figure 1). Categories in the coding book were defined by observations of the shades of foundation provided on each of the 49 beauty brand's web

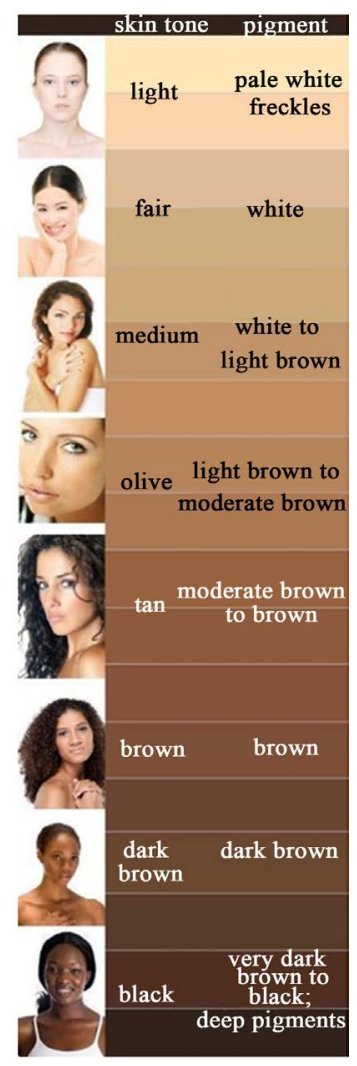

Figure 1. Operationalizations for coding foundation shades offered by brands. 
Table 1. List of beauty brands and total number of foundation shades available.

\begin{tabular}{|c|c|}
\hline Brand & \# \# of Shades \\
\hline ALMAY & 12 \\
\hline ARMANI & 31 \\
\hline ASHUNTA SHERIFF & 6 \\
\hline BAREMINERALS & 30 \\
\hline BEAUTY BAKERIE & 59 \\
\hline BECCA EVER-MATTE & 20 \\
\hline BI-LO (WAL-MART) & 7 \\
\hline BLACK OPAL & 12 \\
\hline BLACK RADIANCE & 12 \\
\hline BLACK UP & 18 \\
\hline BOBBI BROWN & 30 \\
\hline COLOUR POP & 43 \\
\hline COVER GIRL & 10 \\
\hline COVER GIRL-FULL SPECTRUM & 20 \\
\hline COVER FX & 25 \\
\hline DIOR & 12 \\
\hline DIOR-BACKSTAGE & 40 \\
\hline E.L.F. & 11 \\
\hline ELCIE MICRO SILQUE & 12 \\
\hline ESTEE LAUDER & 56 \\
\hline FASHION FAIR & 12 \\
\hline FENTY & 4 \\
\hline GLOMINERALS & 20 \\
\hline HARD CANDY & 9 \\
\hline IMAN COSMETICS & 12 \\
\hline L. A. GIRL & 18 \\
\hline II MAKIAGE & 50 \\
\hline L'OREAL & 43 \\
\hline LANCOME & 185 \\
\hline LAWS OF NATURE COSMETICS & 21 \\
\hline LUMINESS & 12 \\
\hline LUSH & 40 \\
\hline MAC & 61 \\
\hline MAKEUP FOR EVE/MR & 43 \\
\hline MAYBELLINE & 16 \\
\hline MELANIN FOR GIRLS & 9 \\
\hline
\end{tabular}




\begin{tabular}{lcc} 
Continued & & 29 \\
\hline MILANI & 2 \\
NARS VELVET & 14 \\
NEUTROGENA & 120 \\
NYX & 8 \\
PHYSICIANS FORMULA & 16 \\
POSNER COSMETICS & 18 \\
RCMAVVK PALETTE & 16 \\
REVLON & 25 \\
RIMMEL & 40 \\
SMASHBOX & 40 \\
TARTE & 9 \\
TOM FORD & 9 \\
URBAN DECAY & 26 \\
Total Shades Available* & 1374 \\
\hline
\end{tabular}

${ }^{*}$ As of February, 28, 2019. Note: For further reference, see

https://www.elle.com/beauty/makeup-skin-care/g21253742/makeup-lines-wide-foundation-ranges/.

pages. Revisions were made along the coding process to make sure coded categories of skin tones and pigments were as exhaustive and mutually exclusive as possible. The third and final coder made judgments about all the codes provided in the sample. Forty-nine beauty brands were obtained by conducting an extensive search via Google, phone calls to department stores, reviewing magazines, and database queries assisted by journalism media librarians.

\subsection{Unit of Analysis and Coding Categories}

The unit of analysis was the 49 beauty brands as identified previously in Table 1. The author used databases and Google to identify top beauty brands used by women of all backgrounds. Each brand was coded in the following categories: where the cosmetics are available for purchase, type of foundation shades that ranged from $1=$ light, $2=$ fair, $3=$ medium, $4=$ olive, $5=\tan , 6=$ brown, $7=$ dark brown, and $8=$ black, total number of shades available, and whether the product was created specifically for women of color (e.g. $1=$ no, $2=$ yes). Figure 1 , again, depicts the color chart that was used to code foundation shades.

If a foundation shade was observed in the skin tone/pigment category, a number " 1 " was placed in the coding category to show that the shade was available. If the shade for the pigmentation was not available, a "0" was coded to represent "not present". We then coded the number of shades, if provided, that were available in the pigment/skin tone category. This coding category led to the creation of a variable "total shades offered" which was a summation of all the skin tones and levels of pigmentation offered by each beauty brand.

One important note must be considered in terms of coding of shades and 
pigment. The coding of shades was a rough proxy for inclusivity. Keep in mind that liquid foundation often changes when it is applied to skin, therefore it must be noted that a valid tabulation of exact matches to skin tone was not calculated. We did not code how a liquid foundation changes when it is applied, or, whether it is effective across different undertones and skin types. Thus, our coding did not take into account how the shade looks on various skin tones-therefore it is important to keep in mind that the findings obtained in this formulative study, a study that is rare and unique, represents just one piece of a much-needed larger study.

Next we measured sales venues for the foundations provided by beauty brands. We measured whether or not the brand was available through discount stores like $1=$ variety stores like Wal-Mart, Walgreens, Target, $2=$ retail stores such as Macy's, Kohl's, J. C. Penny, to name a few, $3=$ E-commerce (i.e. direct marketing and online sales), $4=2$ or more retail venues. In order to avoid duplication of data, we did not code product shades that were available in all three venues-this was deemed the more appropriate for better clarity of the findings, particularly when some brands were only offered in one of three venues.

\subsection{Coding Reliability}

To maintain consistency in data collection, the coding guide was continually referenced during the coding process. Before coding of the entire sample began, the author checked inter-coder reliability until an agreement of at least $80 \%$ was reached for all coding categories. If coders disagreed more than $20 \%$ of the time, operationalizations of the coding category were reworked until the agreement reached $80 \%$ or higher (Neuendorf, 2017). New coding categories did not emerged during the training or data collection process. The coders were asked to analyze $20 \%$ of the beauty brands in the selected sample. Inter-coder reliability showed 97.9\% agreement, well above the recommended 80\% threshold. Each coding category also resulted in a high inter-coder reliability agreement: beauty brand (100\%), shades $(94.3 \%)$, and availability of product purchase $(99.8 \%)$. Due to high agreement rates in the initial analysis, this explains why newer coding categories were not incorporated into the study after training and further inter-coder reliability was also unnecessary.

\subsection{Data Analysis}

Since the overall purpose of the current project was to determine if beauty brands have added darker shades for women of color making it easier for women to find make-up that matches their skin tone. The main research goal was to compare the relationship between beauty brands and the depth of skin tones offered in the foundation marketed and sold in stores, on the web, or in discount stores. Given the research question and goal, a Kruskal-Wallis one-way ANOVA, a non-parametric method for comparing independent samples, was used to analyze data obtained in this study. 
The Kruskal-Wallis nonparametric tests has distinct advantages; it was believed that this was the best way to analyze data on shades of foundation by the 43 beauty brands. Since the data obtained was nominal and as we previously discussed, coding of the foundation shades was measured with some imprecision, a nonparametric test was relatively simple to conduct.

It was also determined that a nonparametric test was most appropriate for the current research for these reasons:

1) Non-parametric tests deliver accurate results even when the sample size is small.

2) Non-parametric tests are more powerful than parametric tests when the assumptions of normality have been violated.

3) A nonparametric test is suitable for all data types, such as nominal, ordinal, interval or data that has outliers.

\section{Results}

Descriptive statistics were used to analyze the coded data by implementing MAC SPSS 20.0 (Statistical Package for the Social Sciences) software. To answer the research question that served as the foundation for the study (What shades are marketed by beauty brands, and has availability of shades for women with darker skin tones more readily available? In other words, have there been any changes in shades over time?). To answer this, descriptive statistics that included frequencies and percentages were conducted for each beauty brand. Frequency analyses were also conducted to answer RQ1: (Do beauty brands have skin tones and shades that more closely resemble women of darker skin tones and pigmentation?) and RQ2: (Are women of color having difficulty finding foundation to match skin tone? To what extent will darker shades be offered in other outlets like variety stores, retail stores, and online, e-commerce outlets?).

RQ1: To what extent are cosmetics available for skin tones that more closely resemble women of darker skin tones and pigmentation?

A series of nonparametric tests were conducted with $p$-values for two independent proportions. Following statistical analysis, the results were interpreted in relation to the literature with a focus on issues related to colorism in the cosmetic industry. Grouping each brand's shades by their lightness values, we first sought to determine how the shades were distributed. By comparing the number of shades the 49 brands offered in each shade range, we can visually determine if there is support in the market for a greater range of skin tones, excelling on both the darkest and lightest ends of the spectrum.

We analyzed shades within the cosmetic industry, namely foundation using frequencies, and the results indicated that light shades $(n=267)$ and medium shades $(n=247)$ was seen more often than fair shades $(n=195)$, olive shades $(n$ $=201)$, tan shades $(n=176)$, brown shades $(n=161)$, dark brown shades $(n=$ $96)$, and black shades $(n=31)$. As reported in the literature review, at one point in American culture, the only scale of tones available was for women of color 
with complexions labeled as "light to moderate/medium". Later, in the 1940s we saw the expansion of three more shades, totaling six total shades that were also expected to included women of darker skin tones. However, as data collected in this study shows, as of 2019, the darker end of the skin tone spectrum is not only available but does exist (see Figure 2). Figure 2 also shows that skin tones with the largest number of pigmentation shades available were found in the light, fair, and olive skin tones. And data shows the availability of foundation shades that should match women whose pigmentation may match more with the dark brown/black skin tones.

Because frequency analysis does not give a $p$-value, a series of follow-up nonparametric tests comparing proportions between shades was conducted. One of the follow-up tests was a Kolmogorov-Smirnov test, a test that is used to indicate if the total shades of foundation found in the sample of beauty brands follows a normal distribution. Results of this test revealed that the number of shades in the eight skin tones does not follow a normal distribution which further supports the idea that there are more shades in the lighter skin tones than darker skin tones, $\mathrm{D}(49)=.360, p=.0000$. The Kolmogorov-Smirnov test is frequently used to test the normality assumption for smaller sample sizes and is equated with analysis required by many statistical tests such as ANOVA, the t-test regression analysis. Therefore, this test was conducted particularly given the small sample size.

Next, a chi-square goodness-of-fit test was conducted. This test was used to determine whether the distribution of cases (e.g. beauty brands) in a single categorical variable (e.g. skin tones) consisting of eight groups: (light, fair, medium, olive, tan, brown, dark brown, black) follows a known or hypothesized distribution

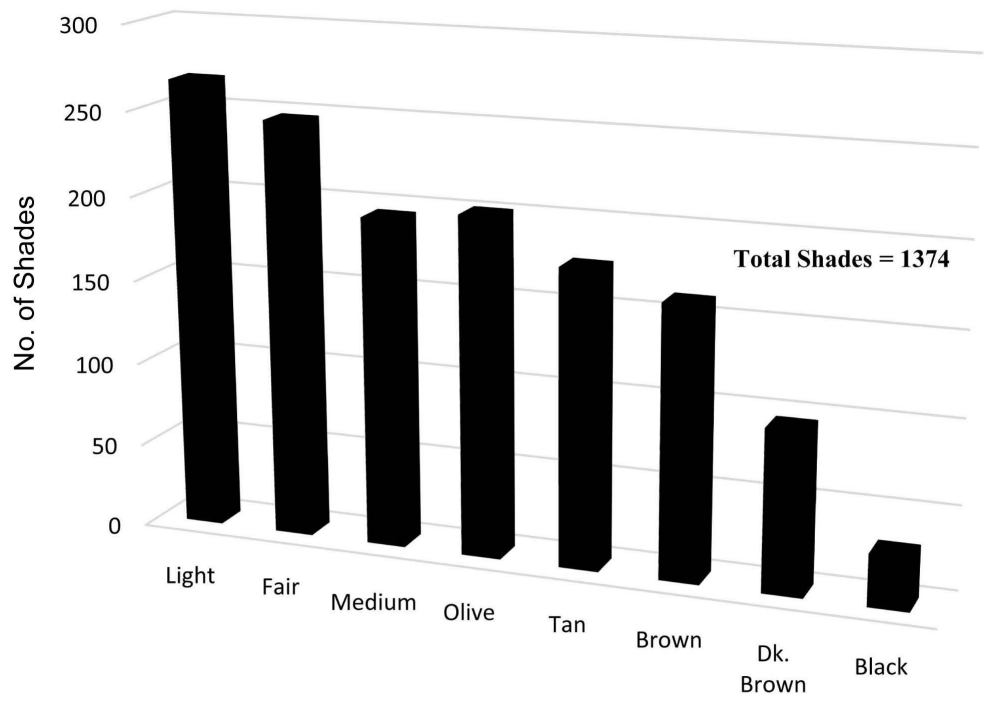

\begin{tabular}{|c|c|c|c|c|c|c|c|c|}
\hline & Light & Fair & Medium & Olive & Tan & Brown & Dk. Brown & Black \\
\hline meries 1 & 267 & 247 & 195 & 201 & 176 & 161 & 96 & 31 \\
\hline
\end{tabular}

Figure 2. Total number of foundation shades offered. 
(e.g. the proportion of shades in a beauty brand that we anticipate for darker skin tones). This test assumes that the proportion of cases expected in each group of the categorical variable are equal or unequal. Results provided by the analysis shows that the shades provided in beauty brands are not equally distributed ( $\chi^{2}=68.7$, df, 55, $p<.0001$ ). This suggests that significant differences exist between the total number of foundation shades offered by beauty brands with higher numbers of shades found in the "light to medium" skin tones.

RQ2: How difficult is it to foundation for darker skin tones? To what extent will darker shades be offered in other outlets like Variety stores (e.g. Wal-Mart, Target, etc.), Department stores, and online, E-commerce outlets?

Chi-square results shown in Table 2 reveal a statistically significant difference in purchase venue of foundation shades among the eight skin tone groupings ( $p$ $<.0000)$. E-Commerce venues are more likely to offer darker shades than are the variety and department store venues.

\section{Discussion}

"If you' re a cosmetics company that's coming to market and you have the old school six to eight shades of foundations, then you' re behind the times." (Hope, 2016).

In doing this study, the goal was to examine changes in the types of shades and tones offered in foundation by the beauty industry-scientific and experiential. The overarching purpose guiding this study was to determine whether changes, enhancements and improvements in make-up have been made since the 1940s. Data obtained in the study show that many beauty brands are now including black and brown skin of various ethnicities, particularly in terms of foundations and concealers. Beauty brands are starting to positively serve the

Table 2. Results of chi-square test and descriptive statistics for purchase venue by foundation shades.

\begin{tabular}{ccccc}
\hline \multirow{2}{*}{ Shade/Skin Tone } & \multicolumn{3}{c}{ Purchase Venues } & \multirow{2}{*}{ Totals } \\
\cline { 2 - 4 } & Variety & Department & E Commerce & \\
\hline Light & $92(35 \%)$ & $89(33 \%)$ & $85(32 \%)$ & 267 \\
Fair & $96(39 \%)$ & $91(37 \%)$ & $60(24 \%)$ & 247 \\
Medium & $70(36 \%)$ & $70(36 \%)$ & $55(28 \%)$ & 195 \\
Olive & $69(34 \%)$ & $73(36 \%)$ & $59(30 \%)$ & 201 \\
Tan & $59(34 \%)$ & $62(35 \%)$ & $56(31 \%)$ & 176 \\
Brown & $49(30 \%)$ & $51(32 \%)$ & $61(38 \%)$ & 161 \\
Dark Brown & $4(4 \%)$ & $3(3 \%)$ & $89(93 \%)$ & 96 \\
Black & $0(0 \%)$ & $1(3 \%)$ & $30(97 \%)$ & 31 \\
Totals & $439(32 \%)$ & $440(32 \%)$ & $495(36 \%)$ & 1374 \\
\hline
\end{tabular}

Note: $\chi^{2}=45.9$, df, $9, p<.0000$. Numbers in parentheses indicate row percentages. 
female consumers and have clearly made the availability of shades for darker skin tones more accountable. It may also be implied that imbalances in shades may be shrinking and that the progress documented in this study may also suggest that women of color will find darker shades. While data suggest that the gap in availability of shades appears to be shrinking toward progress and inclusivity, the idea that there may be more shades available but there isn't one "for me" is still relevant for women of darker skin tones, especially when looking for shades to make their skin tones in outlets such as variety and department stores. Significant differences were found in the relationship between outlets and shades available in the stores. That is, data revealed that foundation shades for the darker skin tones are primarily marketed and available online.

\subsection{Future Research}

As mentioned earlier, this study, while formulative and exploratory, was conducted in order to establish ideas for future extensive research testing changes in the cosmetic industry and their willingness to include women of darker skin tones. Future research may now build on the data provided in this study by first investigating the mission statements of each beauty brand. Retailers and companies have, over the years, began designing and implementing a wide range of diversity initiatives. For example, we find diversity mission statements displayed in company marketing brochures, efforts to expand diversity training, and an increase in events that celebrate and highlight various racial and ethnic groups within a corporation. However, efforts at promoting diversity and inclusion are often met with push back potentially due to concerns about the superficial sentiments regarding the mission and true passions of the company's desire to include people of different races and ethnicities.

Future research might employ a theory that builds upon recent research on colorism and show how cultural ideologies shape various aspects of marketing and product development in the beauty industry (e.g. Heine \& Norenzayan, 2006; Knowles, Lowery, \& Schaumberg, 2010; Plaut, 2002; Plaut, Thomas, \& Goren, 2009; Sanchez-Burks, Bartel, \& Blount, 2009). Two cultural ideologies known as multiculturalism and color blindness (see Park \& Judd, 2005; Plaut, 2002; Wolsko, Park, \& Judd, 2006; Wolsko, Park, Judd, \& Wittenbrink, 2000) offer ideas on how organizations should meet the needs of consumers living in a diverse society (Markus, Steele, \& Steele, 2000; Plaut, 2002).

The color-blind model emphasizes that people are basically the same, that racial categories should be ignored or avoided, and that differences based on social identity should be assimilated into an overarching unifying category. In contrast, the multicultural model-illustrated by the metaphor of a mosaic whose individual pieces are distinct yet together form a coherent picture-explicitly acknowledges differences among groups and promotes the notion that differences associated with unique social identities should be valued and even celebrated. Research in this area might, for example, explore each beauty brand's mission and code the extent to which a company is relying on a cultural color-blindness 
ideology or a multi-cultural ideology. Then, researchers could compare the number of shades available by the brand and provide data that may address the validity and sincere nature of the brand's increase in beauty shades, particularly since some brands have been accused of creating darker shades just for profit and not for need. Research should be conducted that helps to offer an objective, scholarly explanation for why some products are available on-line and not in specialty retail stores. It is quite possible that many retailers may lack the appropriate target market for darker shades in their cities/towns, and therefore the products are not offered in stores. This, once again, is an research area that has been largely untapped and research that helps people of color understand the whys and why nots may also shed light into other areas that will unite us and close the gap on colorism, particularly in the cosmetic industry.

\subsection{Conclusion}

Studying colorism in the beauty industry phenomenon provides a window of opportunity for understanding the depths behind the pervasive problem facing women of all skin tones in American culture. By learning more about the beauty industry, practitioners will be able to systematically incorporate diversity and inclusivity concepts that adequately address attractiveness and ideals concerning beauty in American culture. The need for this exploratory research is particularly great as scholarly initiatives to address this problem have been met with less than favorable results.

While the answer to the research question posed in this study may appear on the surface to be a simple one-just create more shades-we must understand and recognize the larger issue and the motivation for this exploratory research. In terms of certain topics that focus on inclusivity and diversity, we have, in this culture, an issue of ignorance and bias in addressing colorism in the marketing of cosmetics. While there may be more shades available for darker skin tones and complexions, there still seems to be a "but there isn't one for me" phenomenon found in comments on social media. In light of the extensive research on colorism, diversity and inclusion and the many articles arguing to address colorism in media, it is surprising that more progress has not been made in understanding colorism in the beauty industry. However, it is believed that data obtained in this study provides a basis for stimulating research on colorism that is focused on communicating changes and progress made in the industry. Broader research on colorism and improvements (or the lack of) in other areas such as beauty has the potential to provide important benefits to individuals, groups, and organizations.

In the future, a collection of studies on dark skin tones and changes in the frequency of depictions and exposures of models and women with dark-skin complexions might actually encourage the idea and change the narrative concerning what is beautiful. The fact that the cosmetic industry has made changes that show that they increased their traditional six-eight foundation shades to proving $40+$ shades, including shades for darker skin tones. Perhaps more mes- 
saging and more depictions of these darker skin tones with the tag line \#Color Me Black and Beautiful, could finally strategically communicate a persuasive idea that despite your skin tone, you are a women with sophistication; despite its brightness or darkness commands automatic respect and you are beautiful, valued, respected, and loved.

\section{Acknowledgements}

The author would like to express gratitude to the blind reviewers for their insights and guidance on this manuscript. Thank you to the coders who volunteered their time to train, code, and validate the variables under investigation in this important and innovative research study.

\section{Conflicts of Interest}

The author declares no conflicts of interest regarding the publication of this paper.

\section{References}

Berger, A. (1991). Media Research Techniques. Newbury Park, CA: Sage.

Bryant, T. (2016). How The Beauty Industry Has Failed Black Women. https://www.refinery29.com/en-us/2016/02/103964/black-hair-care-makeup-business

Denzin, N. K. and Lincoln, Y. S. (2005) Introduction: The Discipline and Practice of Qualitative Research. In N. K. Denzin, \& Y. S. Lincoln (Eds.), Handbook of Qualitative Research (3rd ed., pp. 1-32). Thousand Oaks, CA: Sage Publications.

Fears, L. M. (1998). Colorism of Black Women in News Editorial Photos. The Western Journal of Black Studies, 22, 30-36.

Goins, L. (2019). The Makeup of Makeup: Decoding Foundation. https://www.webmd.com/beauty/features/decoding-foundation\#1

Goodine, M. (2018). How Colorism Subjugates Dark Skin Women. http://www.grassrootsdc.org/2018/10/how-colorism-subjugates-dark-skin-women-prt-3/

Hall, R. (1995). The Bleaching Syndrome: African Americans' Response to Cultural Domination Vis-à-Vis Skin Color. Journal of Black Studies, 26, 172-184. https://doi.org/10.1177/002193479502600205

Harmon, S. (2018). Black Consumers Spend Nine Times More in Hair \& Beauty. https://www.hypehair.com/86642/black-consumers-continue-to-spend-nine-times-mo re-in-beauty-report/

Heine, S. J., \& Norenzayan, A. (2006). Toward a Psychological Science for a Cultural Species. Perspectives on Psychological Science, 1, 251-269. https://doi.org/10.1111/j.1745-6916.2006.00015.x

Hope, C. (2016). The Makeup Industry's Frustrating Cycle of Struggle and Progress for Women of Colo. https://jezebel.com/the-makeup-industrys-frustrating-cycle-of-struggle-and-1782880385

Hunter, M. (2007). The Persistent Problem of Colorism: Skin Tone, Status, and Inequality. Hoboken, NJ: Blackwell Publishing.

Knowles, E. D., Lowery, B. S., \& Schaumberg, R. L. (2010). Racial Prejudice Predicts Opposition to Obama and His Health Care Reform Plan. Journal of Experimental Social 
Psychology, 46, 420-423. https://doi.org/10.1016/j.jesp.2009.10.011

Krippendorff, K. (2004). Content Analysis: An Introduction to Its Methodology(2nd ed.). Thousand Oaks, CA: Sage Publications.

Marketing News (2018). Multicultural Shoppers Set Pace in Beauty Care. Marketing News, 52, 1-112.

Markus, H. R., Steele, C. M., \& Steele, D. M. (2000). Colorblindness as a Barrier to Inclusion: Assimilation and Non-Immigrant Minorities. Daedalus, 129, 233-259.

Mittell, J. (2004). Genre and Television: From Cop Shows to Cartoons in American Culture. New York: Routledge.

Moné, B. (2018). 4 Times Beauty Brands Were Dragged for Having a Limited Range of Foundation.

https://www.thisisinsider.com/beauty-brands-called-out-for-not-enough-foundation-s hades-2018-7

Neuendorf, K. A. (2017). The Content Analysis Guidebook (2nd ed.). Thousand Oaks, CA: Sage.

Nittle, N. K. (2018a). Before Fenty: Over 100 Years of Black Makeup Brands. https://www.racked.com/2018/1/23/16901594/black-makeup-brands-history

Nittle, N. K. (2018b). The Roots of Colorism, or Skin Tone Discrimination. https://www.thoughtco.com/what-is-colorism-2834952

O’Brien, J. (2009). Encyclopedia of Gender and Society. Thousand Oaks, CA: Sage. https://doi.org/10.4135/9781412964517

Park, B., \& Judd, C. M. (2005). Rethinking the Link between Categorization and Prejudice within the Social Cognition Perspective. Personality and Social Psychology Review, 9, 108-130. https://doi.org/10.1207/s15327957pspr0902_2

Payne, T. (2018). Makeup for Melanin Girls Isn't Just Making Products for Women of Color. It's Listening to Them.

https://www.glamour.com/story/makeup-for-melanin-girls-instagram

Plaut, V. C. (2002). Cultural Models of Diversity: The Psychology of Difference and Inclusion. In R. Shweder, M. Minow, \& H. R. Markus (Eds.), Engaging Cultural Differences: The Multicultural Challenge in a Liberal Democracy (pp. 365-395). New York: Russell Sage.

Plaut, V. C., Thomas, K. M., \& Goren, M. J. (2009). Is Multiculturalism or Colorblindness Better for Minorities? Psychological Science, 20, 444-446. https://doi.org/10.1111/j.1467-9280.2009.02318.x

Report Linker (2018). Beauty or Make-Up Product Markets. https://www.reportlinker.com/about

Robinson, T. L., \& Ward, J. V. (1995). African American Adolescents and Skin Color. Journal of Black Psychology, 21, 256-274. https://doi.org/10.1177/00957984950213004

Sanchez-Burks, J., Bartel, C. A., \& Blount, S. (2009). Performance in Intercultural Interactions at Work: Cross-Cultural Differences in Response to Behavioral Mirroring. Journal of Applied Psychology, 94, 216-223. https://doi.org/10.1037/a0012829

Segran, E. (2015). Is the Makeup Industry Finally Embracing Diversity? https://www.racked.com/2015/3/10/8176275/beauty-industry-women-of-color-makeup -cosmetics

Wade, T. J., \& Bielitz, S. (2005). The Differential Effect of Skin Color on Attractiveness, Personality Evaluations, and Perceived Life Success of African Americans. Journal of Black Psychology, 31, 215-236. https://doi.org/10.1177/0095798405278341 
Watson, S., Thornton, C., \& Engelland, B. (2010). Skin Color Shades in Advertising to Ethnic Audiences: The Case of African Americans. Journal of Marketing Communications, 16, 185-201. https://doi.org/10.1080/13527260802707585

Wolsko, C., Park, B., \& Judd, C. M. (2006). Considering the Tower of Babel: Correlates of Assimilation and Multiculturalism among Ethnic Minority and Majority Groups in the United States. Social Justice Research, 19, 277-306.

https://doi.org/10.1007/s11211-006-0014-8

Wolsko, C., Park, B., Judd, C. M., \& Wittenbrink, B. (2000). Framing Interethnic Ideology: Effects of Multicultural and Color-Blind Perspectives on Judgments of Groups and Individuals. Journal of Personality and Social Psychology, 78, 635-654.

https://doi.org/10.1037/0022-3514.78.4.635 